\title{
Massive Open Online Courses (MOOC) within the Framework of International Developmental Cooperation as a Strategy to Achieve Sustainable Development Goals
}

\author{
María José Sosa-Díaz *iD and María Rosa Fernández-Sánchez \\ Department of Educational Sciences, Faculty of Teacher Training, University of Extremadura, \\ 10003 Cáceres, Spain; rofersan@unex.es \\ * Correspondence: mjosesosa@unex.es
}

Received: 21 October 2020; Accepted: 1 December 2020; Published: 6 December 2020

\begin{abstract}
Massive Online Open Courses (MOOCs) offer the opportunity to implement a quality education timetable for those who lack the means due to economic, travel, or temporary availability limitations. Because of this, some non-governmental development organizations (NGOs), working in Latin American countries, are trying to implement this type of educational model within their educational projects. This article presents a case study on the development of a MOOC within the framework of international development cooperation carried out by an NGO and the National Autonomous University of Nicaragua. The research aims to analyze the opportunities and challenges of free, open, online teaching as a tool for achieving Sustainable Development Goal 4, and explore new educational possibilities to train people and contribute to the development of the communities in which they live. From a qualitative approach, grounded theory has been used as a holistic methodology for collecting, analyzing, and interpreting data, allowing the generation of theory in a systematic way. The most effective pedagogical models are evidenced to achieve the learning objectives and observe the challenges to be faced in order to achieve the effectiveness of MOOCs in this context. In conclusion, more applied research is needed to address the challenges that today's societies, in times of pandemic, are facing at an educational and sustainability level.
\end{abstract}

Keywords: MOOCs; sustainability education; Sustainable Development Goals (SDGs); international development cooperation; non-governmental organizations for development; higher education

\section{Introduction}

Today, societies are facing social, economic, health, and environmental crises, which urgently require a paradigm shift based on sustainable development that helps create a society that lives within the ecological limits of the planet, respecting the symbiotic relationship between nature, social welfare, and community development [1,2]. In this context, digital technologies, fully incorporated into our lives, can contribute to creative solutions to meet current challenges, and foster the transformations needed for sustainable development. At an educational level, the Massive Open Online Course (MOOC) has made it possible for people from different parts of the world to access information and obtain knowledge, without prior educational requirements. They thus provide an ideal means of disseminating knowleadge to a mass international audience [3] while forming a global learning community to share experiences and foster the development of critical thinking [4]. Since their emergence, MOOCs have experienced rapid growth and are now an essential model of the current education system that can facilitate training to reach all people more efficiently and equitably, leveraging 
global educational resources [5,6], and becoming an indispensable aspect of the United Nations-driven Sustainable Development Goals.

Despite the lack of consensus on what constitutes the different terms related to the confluence of sustainability and education $[7,8]$, we understand that the term sustainability refers to an improvement in the quality of human life living within the capacity of the support ecosystems [9]. That is, living in an environmentally, economically viable and socially equitable state. One of the key areas for generating and promoting change has been the role of education [10-12]. Indeed, it has been incorporated as a priority objective in the United Nations SDGs, specifically in SDG Goal 4, which aims to "ensure inclusive, equitable, and quality education and promote lifelong learning opportunities for all" (SDG 4). The Sustainable Development Agenda 2030 states that education allows for rising socio-economic mobility and is key to getting out of poverty [6]. This agenda is a global call for action to put an end to the great problems of the planet: ending poverty and inequality, achieving gender equality and access for all to decent work, facilitating access to health services and adequate education, protecting the environment, and ensuring that all people enjoy peace and prosperity. In this new framework, the NGOs (non-governmental organizations for development) have a decisive role, as they participated, together with other NGOs, in consultations prior to the signing of Agenda 2030, considering that once approved, it is essential that they actively participate in its achievement [13]. According to Carricondo et al. [13], civil society entities and specifically NGOs contribute to the achievement of Agenda 2030 by carrying out projects and programs to end poverty, reduce inequalities, and support vulnerable groups. They claim that such actions will have a positive impact on the SDGs and it is therefore important to identify and measure this impact in order to be able to assess their performance and set long-term objectives. Another of the essential roles of these social entities is to raise awareness and advocate politically in order to align action of public authorities with Agenda 2030. In addition, one of the goals of the Agenda is to encourage and promote effective partnerships in the public, public-private, and civil society spheres, drawing on the experience and resource-raising strategies of partnerships. To guide organizations in this task, the SDG Compass Guide has been adapted, translating this framework into the language and characteristics of NGOs. The SDG Compass is a guide developed by the Global Compact, Global Reporting Initiative (GRI), and the World Business Council for Sustainable Development (WBCSD) to help entities contribute to the SDGs [13]. In the context of the Third Strategic Plan of the Third Sector of Social Action, indicators have been established that contribute to Agenda 2030 and their alignment with information gathered to measure contribution to the progress of the SDGs. Objective 4, which we have indicated as referring to education, highlights the goals "to considerably increase the number of young people and adults who have the necessary skills, in particular technical and professional skills, to access employment, decent work and entrepreneurship" and "ensure equal access for all men and women to quality technical, vocational and higher education, including university education." Indicators of this objective include technological innovations aimed at social needs, identification of significant experiences of cooperation with the academic world and new experiences of cooperation involving the joint design or implementation of responses to social needs. From several fronts [14,15], both the rationale and the establishment of indicators of SDG 4 have been criticized for the danger of giving too much attention to standardized assessments, not as a complement, but as a central mechanism for assessing the achievement of the targets. This makes it possible not to address the integral development of people and the construction of critical citizenship as central tasks in responding to this Sustainable Development Goal [15]. From this critical viewpoint, a commitment has been made to promoting lifelong learning, the integral development of personality and happiness, the capacities to fully exercise critical citizenship, and the opportunities to meet job and professional development, all challenges that arise in today's society. Consequently, SDG 4 requires an approach from a critical assessment that goes beyond standardized tests and quantitative indicators [14].

Universities, as higher education entities, are a key instrument for promoting sustainable development [12,16]. Since the UN Declaration of the Decade of Education for Sustainable Development (2005-2014), universities have made an effort to integrate sustainability into their systems but only a 
few have succeeded in implementing it in a comprehensive manner [17]. However, universities are still being urged to continue efforts to achieve this integration and to commit themselves, not only to internal processes related to sustainable development but also to processes of social transformation, with the development of formative models that welcome the social dimension $[12,18]$. This refers to social responsibility and commitment to reduce certain inequalities with sustainable education, in line with the SDGs.

The initiative proposed in this study is based on this frame of reference in which the partnerships between an NGO and the universities allow us to work to strengthen one of the SDGs, from a standpoint that reaches beyond quantitative approaches and standardized assessments.

MOOCs at the university constitute an open, massive, and free system that offers access to high-level training, without distinction as to border, gender, race, class, or socioeconomic level through the democratization of education [19]. These training models, together with higher education are becoming important factors in achieving the goals of SDG 4 [20,21]. Despite this, there are still, but to a low degree, challenges involving low completion rates and problems with quality assurance, accreditation, cultural prejudice, and inclusion for people without digital skills [22-24]. It should be ruled out that these trainings have been perfected over time and that there has been implementation of new pedagogical models that, supported by digital technologies and resources, help students interact with the course content in an active way, reducing the critical aspects of this training model [25-27]. Studies are identified that even suggest that MOOCs should be designed under sustainable, social, and communicative curricular approaches while enhancing interaction in collaborative work [28]. Additionally, these interactions under social learning models support intercultural dialogue, interdisciplinary collaboration, inclusive learning opportunities, awareness of global problems, critical engagement, and knowledge generation [29]. Even in developing countries, this is promoting digital competence among citizens [30].

MOOCs for education and sustainable development have been booming for a few years. A review by Zhan, Fong, Mei, Chang, Liang, and Ma [31] identified more than fifty MOOCs dealing with issues of climate change, ethics, and natural resources, energy, and sustainable development. This type of training is offering students a different perspective, one where they can interact, share opinions, and discuss with people around the world who are facing similar or different issues, seeking shared solutions [32-34]. Even knowledge on sustainable development is being developed, from such experiences, such as the publication of Sachs [35] following the development of the MOOC "The Age of Sustainable Development", which collects interdisciplinary research and reflections on the topics worked at the MOOC.

In Latin American universities, the development of MOOCs took place guided by three motivations: the open concept of learning, the global interaction processes they generated, and the possibility of access to training regardless of the socioeconomic characteristics of the student [36,37]. From this perspective, MOOCs are not only presented as an alternative for higher education institutions, but also as an attractive and potentially powerful tool for non-profit organizations that aim to train those with fewer economic resources. These types of organizations are also currently implementing this open and massive education model, in collaboration with universities that endorse its quality, with the aim of facilitating access to learning for all people who wish to acquire vocational training adapted to their economic, temporal, and spatial needs [38]. These courses are often publicly funded, which is promoting the universalization of higher education in these countries [39]. An analysis of the scientific literature on MOOCs in these universities, shows that this model of training is increasing, with great impact on the educational field and good perception and acceptance by students, in addition to highlighting important changes in methodological and pedagogical designs in the teaching process and learning in virtual environments, and receiving positive reviews from the business world [40].

Nicaragua is beginning to grow in e-learning training implementations. In universities, especially private universities, this training modality is already used, specifically blended learning projects. In addition, the government of Nicaragua is trying to improve educational quality through the use of 
information and computer technologies (ICTs), improving both infrastructure in urban and rural areas and teacher training [41]. As the number of people with access to technologies increases, virtual training can become an alternative for those Nicaraguans who are unable to participate in classroom training. Although Internet access is not yet widespread in Nicaraguan homes, there are many premises that offer these services. NGOs are some of the institutions that offer this service within the country and are allowing groups of people to opt for an emerging training modality, promoting better education and change of educational paradigms. Furthermore, some of these institutions focus on helping to achieve Sustainable Development Goal 4 (SDG 4), ensuring quality education as a pillar for the sustainable development of the communities in which they work.

There is the offer of training, some through MOOC, as in the case of our study, which provides a great opportunity adapted to the needs and interests of the population, and which can help to improve the contexts in which they live.

This collaboration between MOOCs, universities and NGOs, promoting sustainability education (Figure 1), is presented in this article as an interesting combination that, under an eminently qualitative research approach, seeks to learn from the process of implementation of MOOCs and to take into account different elements that could make future applications successful and generate future changes that support the sustainability of the planet. Then, what pedagogical model should be assumed by the universities in alliance with the NGOs in order to implement MOOCs for the development of a quality education in accordance with the interests and needs of the participants? Moreover, what educational possibilities and challenges do MOOCs face for the sustainable development of individuals and communities?

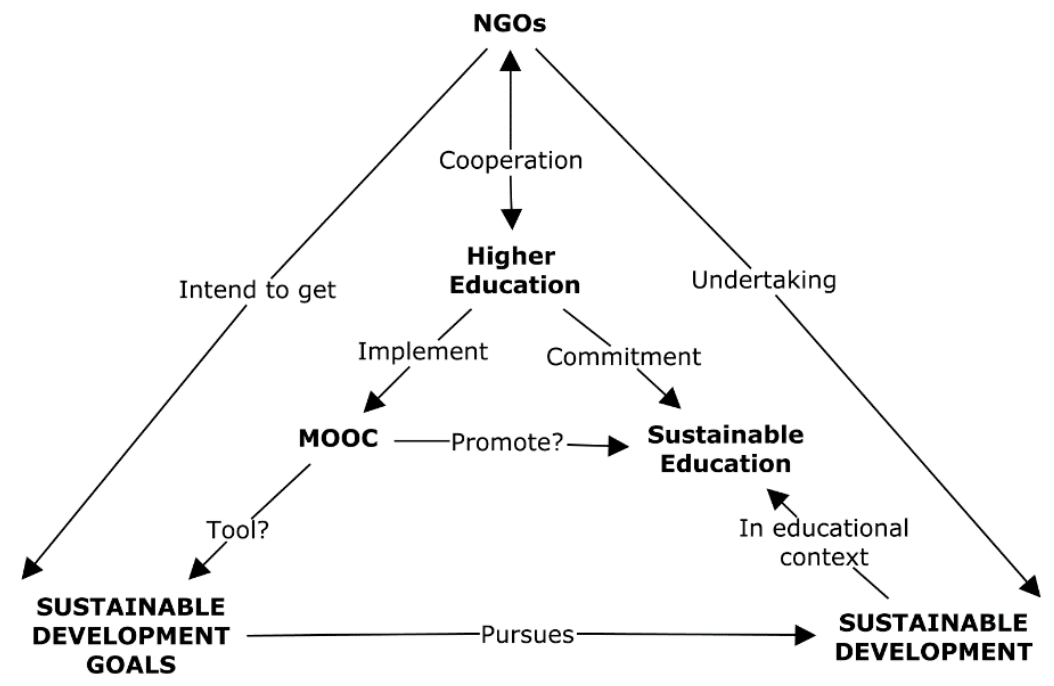

Figure 1. Theoretical model elaborated by the authors.

\section{Materials and Methods}

\subsection{Goals of the Investigation}

The research study carried out aims to analyze the opportunities and challenges of free, open online education as a tool for achieving the Sustainable Development Goal 4, and the possibilities offered by this type of learning to the sustainable development of a country. However, the intention is to go beyond the mere collection of statistical data and to focus on a more qualitative plane, detecting and analyzing the dimensions considered to be most important, in order to generate knowledge about the perception of teachers, managers, and students regarding the educational phenomenon that MOOCs are producing.

In this sense, the specific objectives of this research are: 
- Examine the pedagogical models that universities and NGOs must assume in the implementation of MOOCs, in order to develop a quality and effective education.

- To study the educational possibilities and challenges of MOOCs for the sustainable development of individuals and communities.

\subsection{Investigation Methodology}

According to the characteristics of our research problem and the objectives set out, it was decided that a qualitative methodology would be carried out. This type of methodology implies an interpretative and naturalistic approach to the world [42], which allows us to study things in their natural context, trying to make sense or interpret phenomena in terms of the meanings that people give them [43]. A critical case study was selected, which has particular characteristics that are not common, and which are considered of interest in studying the MOOC phenomenon in depth. This allows us, analyzing from a point of particularity and complexity, to clarify and expand issues that could contribute to existing theory [42,44]. As Stake [42] points out, studying particularity is very valuable because it allows for the obtaining of important information about what happens in the educational reality, that can be transferred to other contexts.

\subsubsection{Case Identification}

The case study, carried out in this research, focuses on the analysis of a MOOC training course on entrepreneurship training. Some NGOs have established agreements and collaborations with Latin American universities for the development of MOOCs. In this case, we focus on the Knowledge Factory of Nicaragua by ASDENIC (Association of Social Development of Nicaragua), which has established an agreement with the Regional Multidisciplinary Faculty of Estelí (FAREM-Estelí) of the National Autonomous University of Nicaragua (UNAN), to take this MOOC training course on entrepreneurship training.

\subsubsection{Case Study Data Sheet}

Name: Entrepreneurial training

Objectives:

- Support enterprising people to define a personal project.

- Guide entrepreneurs in the process of building entrepreneurial skills.

- Develop entrepreneurship.

Modules:

- Module 1: Starting on the entrepreneurial path-Creating a project.

- Module 2: Project Definition

- Module 3: Emotional Intelligence

- Module 4: Language and active listening

- Module 5: Make offers

- Module 6: Assemble the project and its narrative

- Module 7: Create a prototype

- Module 8: Studying the Market

- Module 9: Developing networks and alliances around the project

- Module 10: Defining a work and production plan

- Module 11: Developing leadership skills.

- Module evaluation 
Duration: $120 \mathrm{~h}$ in 13 weeks

Certification: The acquired competencies will be certified by means of an official document signed by FAREM-Estelí (UNAN). The certification will be free of charge to students.

Platform: The platform used for training development was Moodle. The project was created and managed by the NGO ASDENIC, in collaboration with the teachers of FAREM-Estelí (UNAN) who produced the materials and contents.

Registered: 107 students were interested.

Enrolled: 71 students started training.

Obtained certification: 49 students completed the training.

\subsubsection{Context of the Case Study}

The Association for Social Development of Nicaragua (ASDENIC) was founded in 1990 and is a local development agency. ASDENIC aims to promote the social and economic development of rural communities and urban settlements, mainly in the Segovias region of northern Nicaragua.

Within ASDENIC exists the Knowledge Factory, which is defined as a space for the attainment and construction of the future, where the SDGs are pursued through new models for human development. From an innovative vision standpoint, an attempt is made to find new ways to produce goods and services, new ways to create relationships, new ways to learn and undertake, new forms of leadership, or new skills that can improve the development of the community (https://www.asdenic.org/).

One of the main objectives is therefore to advise and train local producers for the improvement of their productions and young university students for the acquisition of soft skills related to entrepreneurial and leadership training. In order to work with these groups, taking into account the idiosyncrasy of the social context and the characteristics of the target audience, the NGO considered it important to implement MOOCs as an alternative to the traditional training that was being conducted so far and as an innovative way of contributing to the Sustainable Development Goals 4: to ensure inclusive, equitable and quality education, and to promote lifelong learning opportunities for all, among the other following goals:

- Target: 4.3 By 2030, ensure equal access for all men and women to quality technical, professional, and higher education, including university education.

- Target: 4.4 By 2030, considerably increase the number of young people and adults who have the necessary skills, particularly technical and professional skills, to access employment, decent work and entrepreneurship.

Following the indicators established within objective 4, in which it is considered important to establish alliances with institutions of higher education, an agreement was signed with FAREM-Estelí of the UNAN. This was key to giving the highest academic formality and diffusion to training. Therefore, the "Entrepreneurship Training" MOOC is part of the program of lifelong learning and specialization courses of the FAREM-Esteli in UNAN, with which the faculty and accreditation are run by the university, being free for the students. However, it is the Knowledge Factory that takes care of student recruitment, pedagogical design, theoretical content, and technological access.

Finally, considering the opportunity to promote the development of other MOOCs in higher education, UNAN offered the possibility to analyze and study the results of the course: "Entrepreneurship Training", to research staff outside of the University of Extremadura, specialists in the subject matter, and those who might obtain objective data useful for future decisions.

\subsection{Data Collection Instrument}

The case study uses different techniques of conversation and narration, such as the semi-structured discussion and interview group, especially qualitative (Valles, 2003). 


\subsubsection{Focus-Group}

The focus-group consists of a structured small group debate led by a moderator [45]. In our research, the focus-group consisted of ten people, nine of whom were teachers and a moderator who guided the discussion. The criteria for the selection of teachers centered around their discipline and their having participated in the MOOC implemented by the National Autonomous University of Nicaragua in collaboration with the NGO ASDENIC. For the selection of teachers, the main criterion was to have participated in the MOOC implemented by the National Autonomous University of Nicaragua in collaboration with the NGO ASDENIC. However, professional discipline and specialty were also identified, to ensure that the group was heterogeneous. All teachers who met the main criteria were sent an invitation by email, explaining the objectives of the research and encouraging them to participate in the focus group. In the end, all the teachers who received an invitation attended the focus group. In the end, a heterogeneous and interdisciplinary group of teachers was assembled, those of whom had had a first contact with the planning, administration, and management of the MOOC. The departments represented in the focus-group were: economic science, education, technology and health, humanities, biology, and environment. Table 1 shows a detailed description of the participants in the focus-group.

Table 1. Description of participants according to role and instrument used.

\begin{tabular}{lllc}
\hline Instrument & Role & Codes & Number of Participants \\
\hline Focus-group & Teacher & P1 P2; P3; P4; P5; P6; P7; P8; P9 & 9 \\
\hline \multirow{2}{*}{ Interview } & NGO manager & R1; R2; R3; & 3 \\
\cline { 2 - 5 } & Student & A1; A2; A3;...; A37 & 37 \\
\cline { 2 - 4 } & MOOC Admin & G1 & 1 \\
\cline { 2 - 4 } & & Total & 50 \\
\hline
\end{tabular}

\subsubsection{Semi-Structured Interview}

The semi-structured interview has been used as the most important resource for information collection [46,47]. The interviews were semi-structured and based on open-ended questions, which were based on preformulated dimensions. The semi-structured interview was conducted on all persons responsible for the training of the NGO and the manager of the MOOC Course "Entrepreneurial Training". The semi-structured interview was also conducted with students who had participated in all of the course's development. For the selection of students, the main criterion was to have participated actively and to have completed the training properly. An invitation was sent by email to 49 students, who were deemed by the training officers to meet the primary criteria. In the end, 37 students were located and interviewed. To ensure the heterogeneity of participants, personal characteristics such as sex, socioeconomic status, and place of dwelling were also controlled. In this way, information was obtained that provides the detail and perspectives of interviewees, allowing the interpretation of data from their experience. Table 1 shows a detailed description of the participants in the interview.

\subsection{Data Analysis: Informed Theory}

Grounded theory was the key to interpreting the qualitative results of this research [48]. As such, the research study focused mainly on two analysis strategies that guided the research process: the method of constant comparison and theoretical sampling.

\subsubsection{Theoretical Sampling}

Theoretical sampling consists of simultaneous analysis and data collection, which allows the investigator to expand the sample when more information is needed [48]. Therefore, the design of this research was conceived as a spiral in three phases, through which it was established what kind 
of groups, informants, and data collection instruments were necessary to explore in order to achieve theoretical saturation [49]. The starting point of the research was to conduct the focus-group among the teachers (open sampling). As the main concepts, categories, and properties emerged, it was considered important to conduct interviews with the managers and administrators of the MOOC course, and thus to obtain more specific information on its development (sampling of relationships and variations). Finally, in order to contrast the information, interviews were developed with a large number of students participating in the MOOC, until theoretical saturation (discriminated sampling) was reached. In the end, in order to contrast information, the necessary interviews were developed until theoretical saturation (discriminated sampling) was reached.

Fundamental theory recommends that the study be started without a review of the technical literature, with the aim of ensuring that concepts, categories, and properties are actually generated from the data [50]. However, although attempts were made to carry out these precepts, a systematic literature review was indeed conducted prior to each theoretical sampling. The objective was to guide the researcher along his process, to afford him knowledge of key aspects pertaining to the subject, that would help in making the necessary decisions in the selection of cases and research tools, as well as familiarizing the researcher with the types of properties and categories that the phenomenon might include [51]. The Appendix A provides a look at the possible properties and categories identified at the beginning of the theoretical sampling and some of the specific questions that were developed to obtain information about these properties and categories and also the participants to whom the questions were asked.

\subsubsection{Constant Comparison Method}

Grounded theory integrates coding and theory generation in a systematic way through an analytical procedure of constant comparison, developing categories and properties [48,52]. In the present investigation, the constant comparison procedure was rigorously followed in four stages:

1. Open coding, data comparison: The initial task of the analyst was to codify each event to form as many categories of analysis as possible, suggested by the data itself [52]. The first step was to perform a "line by line analysis", or what Strauss and Corbin [51] define as a microanalysis. This coding involved a detailed and thorough study of data, sentence by sentence, and sometimes word by word. This analysis involved an initial interpretation that then enabled the discovery of categories and subcategories with their corresponding properties [51]. Matrices were used to sort ideas into emerging dimensions and categories, and the first impressions of the data collected in the memoranda were scored. In these matrices, the concept-ideas found were organized and grouped considering the characteristics of the categories, identifying idea markers, and the quantity of repetition [53].

2. Axial coding, integration of each category with its properties: The use of the matrices helped to perform a deep analysis to synthesize and select only what was considered most important. This procedure highlighted the most common data and where the deviations were, allowing us to consider, reflect, and determine what the main ideas were and answer questions like: Why? Where? When? With what?- -those which pertain to axial coding [51]. In addition, the grouping of concept-ideas into matrices allowed the definition of the properties and characteristics of each concept-idea, establishing the structure of dimensions, categories, and subcategories. Subsequently, keys were sought in the data that denote the relationship between categories and subcategories in the memoranda, used to sketch and construct the conceptual map that allowed the visualization of concepts and their relationships [54]. As research progressed and data analysis yielded new concepts/ideas and new relationships, each of the conceptual maps were modified. This facilitated the analysis and understanding of the data, as well as the subsequent extraction of conclusions.

3. Selective coding, delimit the theory that begins to develop: The analyst at the end found coded data, structure of categories and dimensions, memoranda, and a possible theoretical postulate 
shown in conceptual maps. The researcher analyzed each of them again to inform and delimit the theory and conclusions [54].To this end, a theoretical write-up was realized to recount the relationships between categories and subcategories found, all as a result of the research [51]. In addition, it was considered appropriate in the theoretical writing to identify quotations directly from aspects of interviews or conversations, in order to gain credibility and clarity in the narrative [48].

4. Theoretical saturation of incidents specific to each category: Data collection was terminated, as no new ideas and relationships emerged that expanded the investigation $[49,52]$.

\subsubsection{Dimensions and Categories}

As shown in Table 2, The result of the different coding phases of the constant comparison method resulted in the following system of dimensions, categories, and subcategories, which allowed us to structure the results and construct the theory.

Table 2. Emerging category system.

\begin{tabular}{|c|c|c|}
\hline Dimension & Category & Subcategories \\
\hline \multirow{3}{*}{$\begin{array}{l}\text { Sustainability education: } \\
\text { Teaching characteristics of } \\
\text { MOOCs that address current } \\
\text { challenges, and promote the social } \\
\text { transformations needed for } \\
\text { sustainable development. }\end{array}$} & $\begin{array}{l}\text { Implementation: Vision of the } \\
\text { possibilities of developing } \\
\text { MOOCs in higher education. }\end{array}$ & $\begin{array}{l}\text { Digital culture; teacher training; } \\
\text { infrastructures; analyze; } \\
\text { proposals; future }\end{array}$ \\
\hline & $\begin{array}{c}\text { Pedagogical design: } \\
\text { Type of educational practice } \\
\text { developed. }\end{array}$ & $\begin{array}{l}\text { Contents; materials; methodology; } \\
\text { activities; planning; evaluation }\end{array}$ \\
\hline & $\begin{array}{l}\text { Interaction: } \\
\text { Communication between } \\
\text { members of the } \\
\text { educational community. }\end{array}$ & $\begin{array}{l}\text { Learning community; } \\
\text { collaboration; teaching role; } \\
\text { student role; cultural openness }\end{array}$ \\
\hline \multirow{2}{*}{$\begin{array}{l}\text { Learning: } \\
\text { Valuation of the acquisition of } \\
\text { skills, personal responsibilities in } \\
\text { the teaching-learning process } \\
\text { with MOOCs. }\end{array}$} & $\begin{array}{c}\text { Personal development: } \\
\text { Analysis of people's level of } \\
\text { development when performing } \\
\text { a MOOC. }\end{array}$ & $\begin{array}{l}\text { Self-learning; creativity; basic } \\
\text { competencies; professional skills; } \\
\text { entrepreneurial capacity; digital } \\
\text { competencies; accreditation }\end{array}$ \\
\hline & $\begin{array}{l}\text { Participation: } \\
\text { Student involvement in their } \\
\text { own learning. }\end{array}$ & $\begin{array}{l}\text { Motivation; desertion; } \\
\text { commitment; discipline; } \\
\text { follow-up; time }\end{array}$ \\
\hline \multirow{2}{*}{$\begin{array}{l}\text { Sustainable development: } \\
\text { Valuation of MOOC elements that } \\
\text { can contribute to creating a society } \\
\text { that respects nature, social welfare, } \\
\text { and community development. }\end{array}$} & $\begin{array}{c}\text { Community development: } \\
\text { Community development analysis } \\
\text { when its members perform } \\
\text { a MOOC. }\end{array}$ & $\begin{array}{l}\text { Critical and participatory } \\
\text { citizenship, business creation, } \\
\text { job search }\end{array}$ \\
\hline & $\begin{array}{c}\text { Reducing inequality: } \\
\text { Analyzing the chances of reducing } \\
\text { inequality when people perform } \\
\text { a MOOC. }\end{array}$ & $\begin{array}{c}\text { Access; massivity; } \\
\text { democratization of knowledge; } \\
\text { free; equitable and } \\
\text { inclusive education }\end{array}$ \\
\hline
\end{tabular}

\section{Results}

Below, the analysis of the results obtained is presented, according to the dimensions and categories studied.

\subsection{Description and Analysis of the Design Characteristics of a MOOC}

The faculty questioned some pedagogical characteristics of MOOCs in promoting a true sustainability education and they argued that there must be a process of reflection in the educational community to assess the educational methodology in order to develop a sustainable quality education. 
"However, we should assess exactly what kind of course we are going to offer, [ . . ] It is important to value. I do think it is interesting to apply it but you have to assess with what thing or type of course we have to implement" (analyze, P2).

As shown in the conceptual map in Figure 2, the result of the analysis of concepts and categories, teachers agreed that the pedagogical models developed must especially favor self-training, based mainly on self-learning and the absence of a teaching role that transmits knowledge.

"Because students are not going to need a teacher, and if they do, the MOOC course no longer works because [the process] has to be one of self-teaching" (methodology, P8).

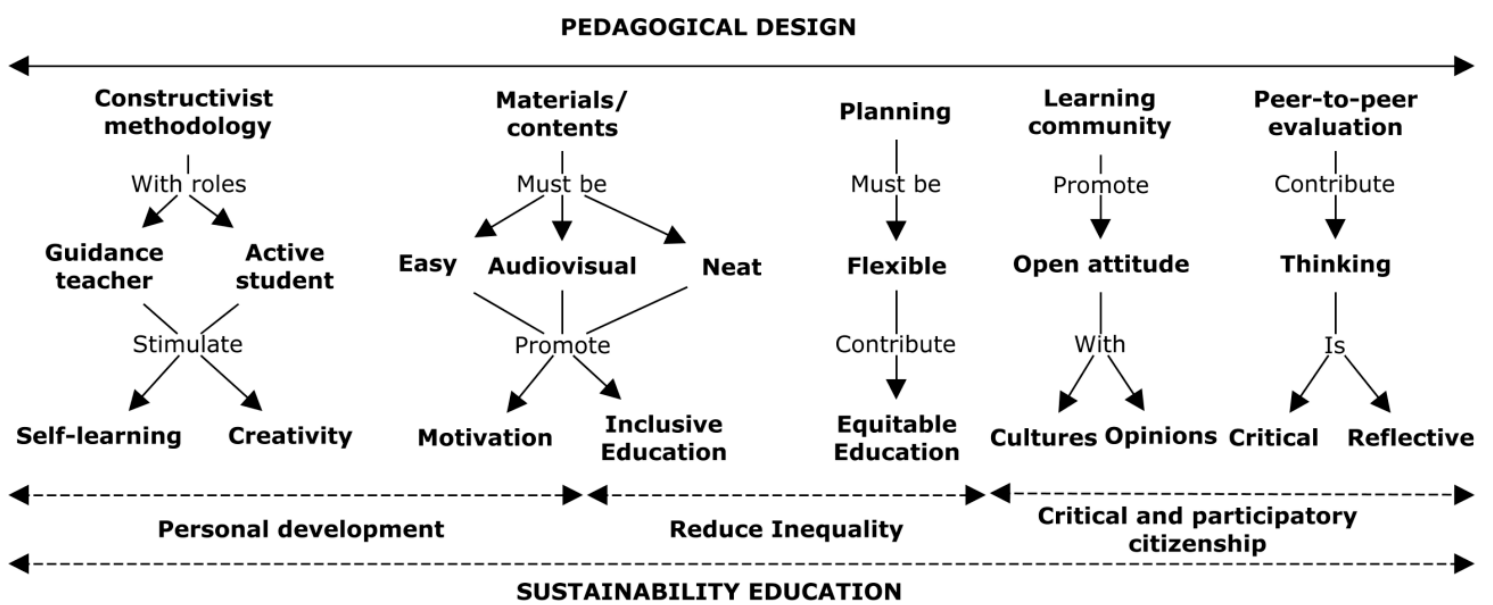

Figure 2. Conceptual map of results on Massive Open Online Courses (MOOC) pedagogical models to develop sustainability education.

In this sense, the activities carried out in the analyzed MOOC "have different characteristics, among which we find: reading and viewing of the material, participation in forums and learning communities, and/or elaboration of a final project" (methodology, G1). In this way, the student is able to develop a learning process that is quite practical and active, which facilitates the process of assimilating content and "putting into practice what we learned in the different modules" (methodology, A14).

In addition, the theoretical content of the MOOC "carries a simple and structured sequence. It doesn't allow you to get lost. Just as it leaves you with a task, it serves you as a sequence for the following" (contents, A32), in a way "that allows students to better identify what steps are to be taken in learning and in creating a business" (contents, G1).

Moreover, the faculty states that materials are a very important element in learning and "they must be simple and very clear for students to understand" (materials, Q8). Students confirm that much of their learning is due to the high quality of audiovisual material and reiterate the importance of using very striking digital formats that appeal to students; "it is better if they are audiovisual" (materials, A16), in order to improve motivation and gain knowledge in a simple way.

"I think that the materials in this type of courses should be attractive enough, motivating and very well structured, so that they also motivate the ... if we put such a text like that, or the same videos, right?" (materials, P3).

Moreover, according to the results, MOOC courses must respond to the needs or expectations of all students to encourage everyone to develop training without complications. The planning of the "activities must be flexible and adapted to our time needs" (time, A20), so that the student can perform them in a comfortable way. However, things should not be too flexible either because the student must have some discipline to complete the course "because people also seem very lazy. It could be like a balance, somewhere in between" (time, Q7). 
In this regard, it is essential that the MOOC administrator or teacher monitor and evaluate the training action and see how it is being adjusted to suit the needs of the student body. This allows for the appropriate decisions to improve the course and keep participants from leaving.

"Because it is free and at any moment one can quit. I have to motivate myself. We have to ask ourselves what we do to finish up, who has really done what, why have they not done something, what is really missing. That will allow us to improve gradually, and the drop-out rate will fall a little bit depending on how. It could be like that. I do not know." (follow-up/desertion, P4).

With all this, a more equitable education will be promoted, that will address the educational needs of each student, especially those without a high level of literacy, and will motivate students to follow through with the training until the end.

The interaction, collaboration, and construction of learning communities are considered essential aspects for good pedagogical design of a MOOC with a sustainable perspective, and fundamental in creating an efficient teaching-learning process. "One important thing is that MOOC courses must be collaborative" (methodology, P3). In this sense, a very useful tool and one which has worked very positively in the analyzed MOOC is a virtual space or social network, where students were grouped by their common interests, of a labor, academic, or recreational nature.

"Don't forget the learning community; it's a space where students can do whatever they want. We say it like that. From uploading videos, to commenting on anything, or how your status is. It is something like a social network and where they can communicate with other people from the same student group, make friends too. [...] That is, the student will feel part of a group. Don't forget how much a course introduces. That is, they have the possibility of communicating with each other" (interaction, R3).

Through this tool it was possible for students to comment on ideas, create groups, send private messages, ultimately break the ice with communication, and develop more collaboration among themselves. Where "one takes into account what another says, what one comments, and yes, just like one takes on what another person says and that's how information travels within the group" (virtual community, A33). People have felt part of a group, feeling comfortable sharing ideas, and valued for their contributions. The student body expressed their opinion and reflection constructively, thus generating new ideas and offering the opportunity to share different views with people who are outside of their social reality.

"I evidence this when students participate in the forums, each one brings something important about a particular topic. This activity becomes enriching as each of us can read what the other colleague has put forth, indirectly helping each other. [...] In the collaboration that is carried out in the forums, each one provides information that can be useful to him for the reflection of other students" (collaboration, A24)

In this way, the self-esteem of participants increased considering that they could contribute to improving the lives of individuals and the community, and also a more open attitude to knowing other possible experiences was fostered, increasing exposure to perspectives and opinions of people from other cultures, and other countries that are alien to their social reality. This allowed the social relationships of participants to expand and led to the production of richer ideas. Such aspects were, according to the participants, very positive and improved learning.

"Sometimes there were colleagues from far away, from other countries and we had the opportunity to share experiences, share opinions. Well, it has been a good experience for me." (virtual community, A28)

In this sustainable pedagogical context, the role of the teacher should have two main functions: on the one hand, as one who administers and creates the MOOC digital materials and on the other, as a guide or someone to orientate within the teaching-learning process. Thus, the teacher is first recognized 
as the expert in a particular subject, one that has the task of providing corresponding material who can answer queries and resolve any doubts related to the content. Secondly, one recognizes the importance of teachers having the ability to manage, organize, and coordinate the activities of the student group participating in a virtual course, as well as mastering the tools available to achieve this.

"The teacher is the one who makes the content itself. [...] He is the one who makes the content and that content transforms into more engaging materials, to make a video for students to self-teach" (roles, $P 7)$.

In this sense, the teacher's follow-up work is very important at all times to maintain continuous contact with the students and encourage them to participate and resolve their doubts. The facilitator must therefore perform essential motivational work by using synchronous and asynchronous communication tools.

"They are always very aware of me. As a student, they wrote, encouraged us and pushed us to complete the work. In general, the faculty displayed a lot of interest, the excellent relationship with me, as a student, very friendly, very open to criticism and resolving doubts" (teaching role, A17).

Among the aspects that invoked more doubts among the faculty regarding the use of MOOCs in the academic field are the evaluation of content. It was stated that it was impossible for the teacher to carry out a continuous evaluation of each student when the course served a large number of people, describing it as "crazy work for the facilitator" (evaluation, P6).

The most recurrent model for solving this situation is peer-to-peer evaluation. It is a type of evaluation that raises many unknowns within the faculty. Doubts arise about the accreditation of content that has been evaluated by the student body, since they may ultimately be influenced by affinity between them or other non-academic aspects.

"Or we have to review others' work, but finally if you don't have technical criteria you tell them that it is okay, just because it is right but not because you know how to do the work" (evaluation, P9).

However, some teachers indicate that this type of assessment can contribute to the development of sustainability education, as it encourages students to be critical and acquire skills to evaluate. Even developing this "type of assessment will contribute to more meaningful knowledge" (evaluation, P8).

However, to obtain these advantages in learning it is necessary that the student have well-defined evaluation criteria from the teacher, which guide the evaluation process.

"And as for evaluation, I think it is difficult because it is massive but if it is done among students, there must be criteria with which all are governed so that they can make a real evaluation. If the criteria remain in the air, what will one evaluate?" (evaluation, $R 2$ ).

In this sense, the student body considers that the evaluation has been adequate and it is noted that it has allowed the student "to improve [their] learning by sharing the project of creation of businesses with others and they have been able to evaluate the idea and bring improvements. This aspect has certainly enriched learning more and improved the business idea" (evaluation, A23).

Therefore, as Figure 2 shows, MOOCs are an opportunity to help reduce inequality and promote sustainable community development. On one hand, MOOC characteristics such as mass formation and free access can promote community development. They offer training to the entire educational community regardless of economy, education, and place of origin, helping to acquire basic and professional competencies, recognized with academic accreditation, which will favor the search for employment, the creation of enterprises, and the development of a critical and participatory citizenship. On the other hand, online features allow for training that is flexible and where travel is not required, which attracts people who live in remote locations and who are not normally able to attend training 
in person. However, this feature provides two main challenges. Firstly, there is a high degree of neglect because online education requires motivation and commitment, and secondly, the educational community is required to have digital skills and digital infrastructures.

\subsection{MOOC Educational Challenges and Possibilities for Personal and Community Sustainable Development}

As the conceptual map shows in Figure 3, results of the research, the interviewees pointed to the opportunity that MOOCs offer to train a large number of people and thereby contribute to reducing inequality and promoting the sustainable development of communities.

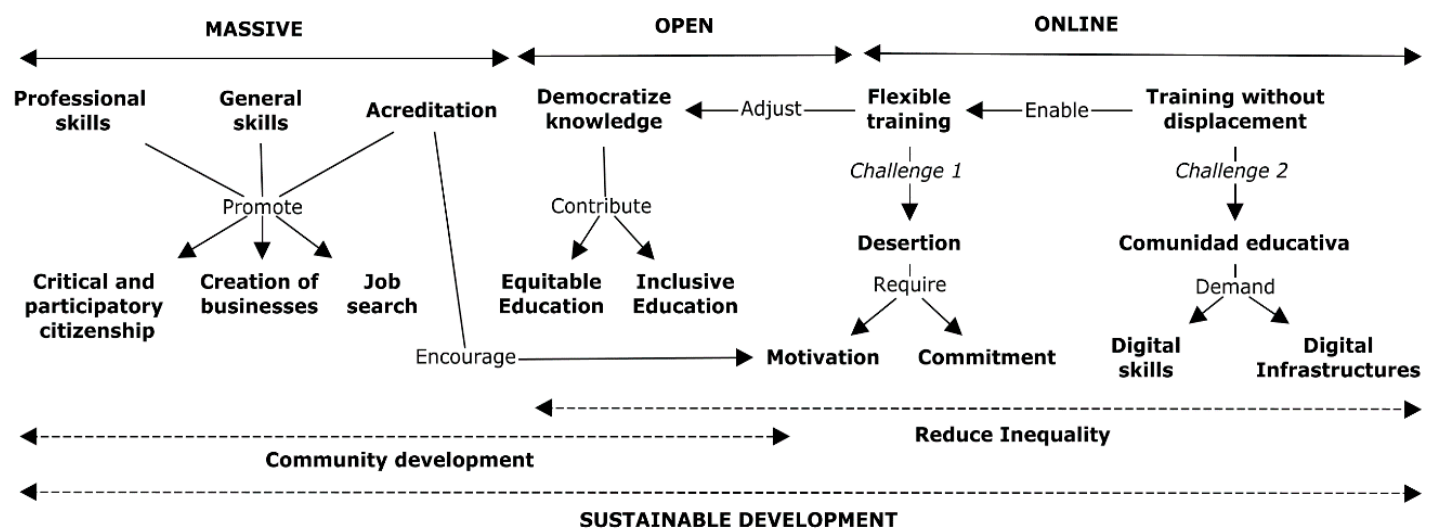

Figure 3. Conceptual map of MOOC opportunities and challenges.

In this sense, the faculty consider MOOCs to be a tool "in the context of the university that would be interesting" (implementation, P1) and very positive. Therefore, the goal of implementing MOOCs within the university academic structure is perceived as a necessity and an aspect that must be addressed as soon as possible.

"We cannot stand on the sidelines as a faculty. The faculty continues to grow, and will continue to grow, but everything we analyze today, has to go through steps and processes. To say no, now, is a mistake. We must try" (future, P5).

The open and free access of MOOCs helps to provide access to quality training for people regardless of educational level, economy, and place of origin, which they could not otherwise obtain. MOOCs are getting to democratize knowledge, "anyone, at any level, motivated by interest, can participate in what is going to take place in that course" (democratization, P7).

"It's somewhat economical, has some quality, and is something that is accessible to many people, very different maybe to other online courses where the price is high because you have to be paying for the platform and all that ... and a lot of other things like materials they deliver. One is also charged the materials that they are paying for" (free, R2).

Furthermore, MOOCs, being online training, favor access to many people living in rural areas where "for lack of time, because they have to work hard and [other courses] are not compatible with their schedules" (access, P8). For these people, regardless of their socioeconomic or personal situation or place of origin, MOOCs provide opportunities to learn about specific topics of interest or importance within their own contexts. MOOCs allow them to carry out training, without displacement and with few economic resources making MOOCs a much more sustainable form of training.

"...The decrease in resources, as I told you before, the student does not have to move to a physical university to get a degree, which they can do perfectly from home, using the resources he already has, such as a phone, a mobile, his computer, the Internet, his tablet. That responds to the need for knowledge, using the resources one already has at hand, not paying much" (access, R1) 
In this regard, participation in the MOOC course "Entrepreneurship Training" was a success. It enabled a large number of people from remote locations throughout the country to be trained and receive professional content and the skills necessary for the creation of a company, and fostered an entrepreneurial spirit. “...Because... as I say to him, [I have learnt] many things I didn't know, and I wouldn't have learned them otherwise. I say yes" (learning, A21). In addition, some students said that "they have gotten the bug for wanting to undertake a company or project for [themselves]" (entrepreneurial capacity, A8). In several cases, this even materialized into the creation of a company.

"The aspects that have improved in my life are first that it helped me to have a clearer view of what I want to do and how to use my talents, such as creating my own company to earn revenue by doing what I like" (entrepreneurship, A14)

It is therefore emphasized that MOOCs allow people to be trained which consequently leads to the development of the community. The environment is influenced by what is the acquisition of knowledge by students who will direct their efforts to transfer learning that contributes to the development of the community in which they live after their training is completed.

"In fact, this kind of process of knowledge, definitely allows people to develop. ...[with] MOOCs using the same dynamic, if there is a development of people, [they] can contribute to the development of their countries. That is very clear" (community development, P5).

However, MOOCs not only offer content and competencies related to entrepreneurship but promote general competencies that participants can use in their daily lives, "which develop[s] the maturity of people" (general competencies, R2), or that one can use in any job, such as "active listening, teamwork and the importance of collaborating with others" (general competencies, A4). In addition, participants acquired skills related to analysis, reflection, and creativity in a way that has contributed to the development of a critical and participatory citizenship.

"...I say yes, because many of the tasks they commanded were quite analytical, it made one reflect. Analyzing things" (general competencies, A37)

The accreditation of the course is a very important aspect with MOOCs, ensuring the certification of the addition of these basic and professional competences. This aspect is one of the elements that participants and course managers pointed to as more positive about MOOCs, since they considered that obtaining such a certificate adds to the $\mathrm{CV}$ and improves the job search process in line with the training.

"[Has professional recognition improved?] A lot, it helps one professionally a lot, this kind of course helps you a lot, both in terms of one's $C V$ and with respect to building relationships, getting a job and starting to relate to people, this opens many doors to you [Would you find a better job?] Of course, because these are opportunities that someone said, affords him knowledge and strengthens his CV. [... ] A boss, an institution, in a company, knowing that one has, the knowledge of entrepreneurs, that one has designed a project, well, I imagine that this affords one a great opening when it comes to hiring" (accreditation, A32)

However, some unknown quantities and suspicions arise for the faculty, mainly due to the evaluation method established by the MOOCs. As such, universities are called upon to be responsible for properly controlling the accreditation process of MOOCs, in order to give this type of training action more quality and validity.

"The other thing is that certification is given by the university. It is a back-up which guarantees that it is academic... It represents a responsibility from the institution and a diploma is given. That person presents the diploma and it is a demonstrable prestige. For a person who has no competence, passing a course at the university and securing the certificate is a responsibility. I think of it like that. One has 
to be very careful. The university gives a degree because one has undergone a process, one has done a lot of work and reached certain levels. It cannot be given gratuitously. One must meet certain student requirements" (accreditation, Q5).

However, obtaining a certificate will be a key aspect to encourage student engagement and motivation for development up until the end of the course, reducing the high dropout rates that MOOCs have. As one teacher points out, "desertion in this type of course is very great" (desertion, P9). The characteristics of MOOCs, according to the interviewees, are very flexible so one needs motivation, and the completion of the course will depend on the student's willingness and discipline in following the classes. As one teacher states "here, as it is free and one can do it whenever they want and whenever they can, one also has to be free" (motivation, P4). In any case, the factor that was considered to be most contributory to desertion is the fact that MOOCs are free. If it is free, the student does not acquire a strong commitment to training, so at the least difficulty or incidence he ends up abandoning because "experience tells us that even a minimum cost to someone brings commitment, because it costs him. Things that are given easily are not highly valued, and then people leave when they feel like it" (gratuitousness/desertion, P2).

Other important limitations in the use of MOOCs were also noted and raised doubts with regards to them being a tool for providing quality and effective training to citizens. They are said to represent quite a difficult and complicated process and "really too abrupt a change for the university" (proposals, P3). Some of the obstacles relate to digital and pedagogical skills and infrastructures, among others.

"However, I believe that in our context we have to ground some things that are necessary for this to happen" (implementation, P9).

As a teacher points out, "thinking a little bit about our context, whether good or bad, we do not have a culture that allows us to take advantage of some courses" (digital culture, P1). On the one hand, students still do not have the digital skills to take an online course, as they do a course in a physical classroom (digital culture, P5).

"At the same time, teachers often "panic about using technologies" (digital culture, P7) and do not have sufficient pedagogical skills. So training is needed "in the process of creating material [...], as well as in evaluating and how to prepare all that" (teacher training, P6).

Furthermore, university technological infrastructures are a great obstacle and are usually not enough to cope with such online courses. Educational institutions are required to "have adequate infrastructure" (infrastructures, P4), and to obtain the digital resources needed to produce quality digital materials.

"The topic of infrastructure for preparation, indeed, we will have to have some technical resources to prepare video, produce quality video and achieve quality of material" (infrastructures, P9).

In addition, technological access for students is an essential aspect in making it possible to carry out a MOOC and determines to a large extent whether or not people can be trained through this educational modality. In the context of Nicaragua, we see that a large part of the citizens cannot have technological access because of the socio-economic context in which they live.

Consequently, student technological access can be a limiting and discriminatory element for people who do not have sufficient financial resources to have computer equipment and access to the network, and this is therefore an aspect that must be taken into account.

"Rather, the problem is a part of the social conditions which exist, which have to do with that access, that a person can have a computer nearby and the necessary conditions to access the course. It is what will make someone participate or not, not the course itself. It is what ensures participation. It is democratic in the sense that it is open to all but it really depends on the conditions that exist in places or countries that will determine whether one gets involved or not" (democratization, P7). 
Therefore, as Figure 3 reflects, there are several pedagogical issues that need to be discussed and reflected on before implementing a MOOC course, so that the pedagogical design of training really develops a quality sustainable education.

In order to reduce inequality and promote development of the participants, the educational community is committed to a constructivist pedagogical model, based on active learning. Here the student's role is proactive and the role of the teacher is process-oriented. All this will favor self-learning and creativity. At the same time, the materials and content must be simple, audiovisual, and very structured, together with flexible training planning, so as to meet all the individual and special needs of the participants and therefore promote more inclusive and equitable education and greater motivation for learning.

This all leads to a critical and participatory citizenship of the community that attends the training. Firstly, pedagogical design must be based on the creation of virtual learning communities, where interaction and collaboration among students are essential aspects, as this encourages an open attitude toward other ideas and cultures. Secondly, peer evaluation must be promoted, which encourages creative and analytical thought and introduction to alternative ways to accomplish tasks or learning.

\section{Discussion}

MOOCs have become a revolutionary new educational model, which can be used by non-governmental development organizations (NGOs) in collaboration with higher education institutions. As can be seen from the theoretical model resulting from the research in Figure 4, MOOCs enable the training of citizens and allow for the achievement of Sustainable Development Goals (SDGs), especially those focused on SDG 4, which aims "to ensure inclusive and equitable quality education and to promote lifelong learning opportunities for all" [31,38].

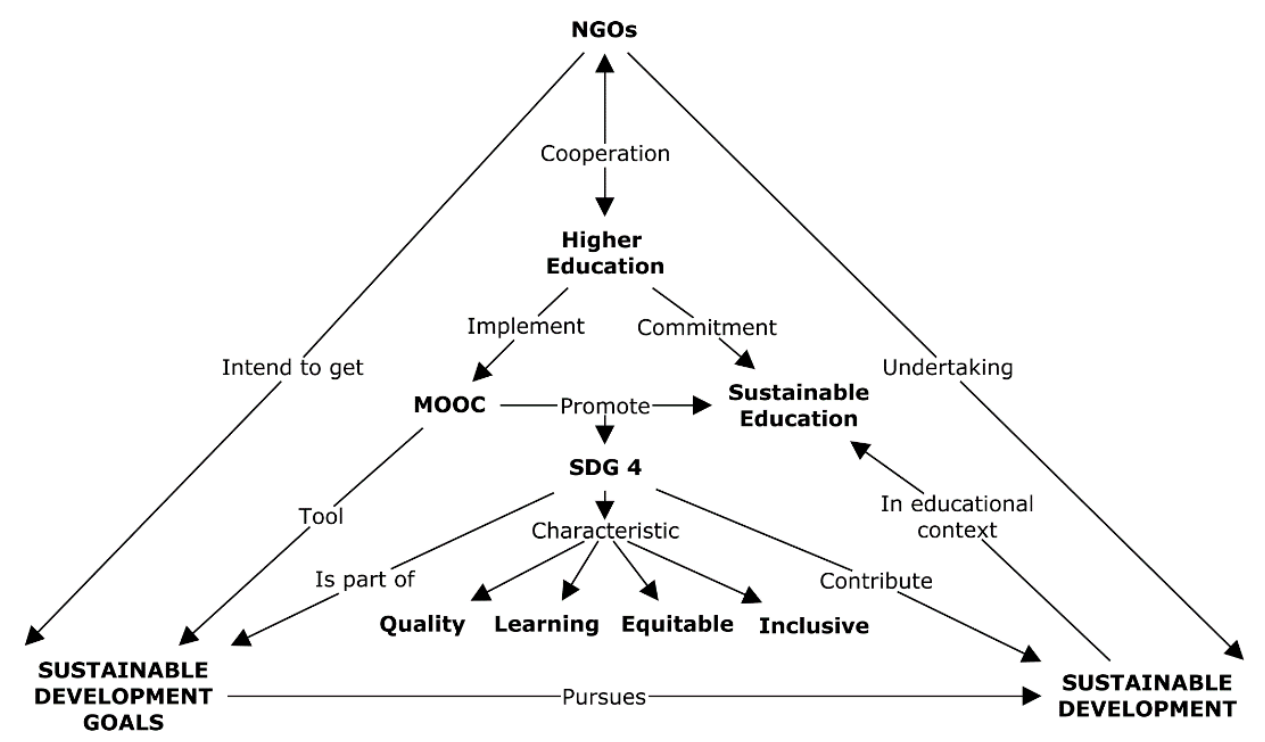

Figure 4. MOOCs as a tool for the development of Sustainable Development Goal (SDG) 4.

MOOCs because of their massive, online and free characteristics are a very useful tool to contribute to sustainable development both at the personal level and at the level of the community in which one lives [5]. In this sense, the development of MOOCs offers the possibility of access to quality training to any person regardless of his geographical location, socio-economic level, or profession $[19,37,39,55]$. From flexible online educational models, the opportunity is created to perform training tailored to the personal characteristics of students. It can therefore be said that MOOCs, in essence, allow citizens to be trained in an equitable and inclusive manner, as the results indicate.

Furthermore, MOOCs not only offer professional content and competencies but also basic skills such as creativity, critical thinking, and self-learning that one can use in daily life and which can 
contribute to a critical and participatory citizenship. These are all aspects that improve the professional recognition of participants and are reflected in a certificate issued by a prestigious university, which can help them find work or create their own company. Therefore, the acquisition of students' knowledge and skills can have an impact on the development of the community in which they live after the training is completed. Thus, following the results obtained, MOOCs can provide a great service to the development of certain disadvantaged communities in Latin America.

However, not all MOOC pedagogical models are valid. As shown in Figure 5, MOOCs conceived of under sustainable curricular approaches must develop pedagogical designs based on constructivism (cMOOC), where the student is the protagonist of his/her learning through active and collaborative methodologies [56,57]. We do not mean that an xMOOC, with teaching model focused on the transmission of information, could not work. They could be critical if they were large-scale courses in which learning analysis informed trainers about student behavior and learning patterns in training [58]. However, given the specific context, in which students are starting with this type of training, a MOOC is needed that has the students as its core focus, rather than the transmission of information typical of the xMOOCs $[59,60]$.

SUSTAINABLE DEVELOPMENT GOALS 4

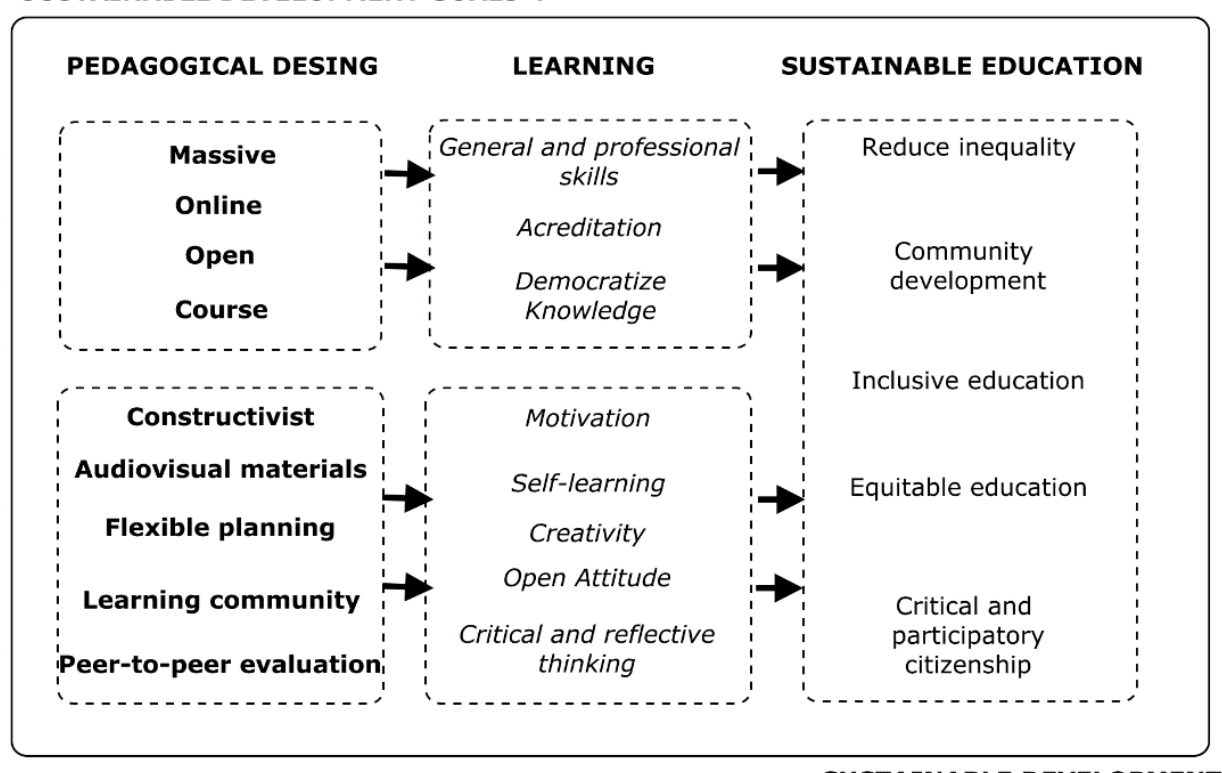

Figure 5. Importance of MOOC pedagogical design to promote sustainable development.

The proposals for activities or projects favor the practical application of content and self-learning, and thus promote creativity and student reflection. In this sense, the role of the teacher who will act as administrator of the formative action, creator of the didactic materials, and in learning orientation must be kept in the background. As for materials, they should be audiovisual, accessible at any educational level, and characterized mainly by their clarity and modular structure, which allows for improved motivation and facilitate learning. Peer evaluation is seen as adequate for evaluating activities, but self-rated evaluation activities could be inserted as an alternative. However, in this type of MOOC, with constructivist approaches, external human feedback is preferable to autonomous feedback [60].

These MOOCs enhance the interaction of collaborative work and promote virtual learning communities. They therefore grant the possibility of interacting, sharing opinions, and discussing with people from different cultures and/or holding different viewpoints, which increases the self-esteem of participants, enriches learning, and opens up ideas [32-34]. In such a way, the construction of a critical and participatory citizenship is encouraged. 
However, MOOCs, as the results show, still raise many unknowns about their development in universities and must overcome certain challenges, including high dropout rates, infrastructure and technological resources of universities and citizenship, acquisition of digital skills of teachers and students, and evaluation and certification of studies offered [22-24]. These issues have a very close relationship with the pedagogical design of MOOCs [61,62].

\section{Conclusions}

In this article we highlight the opportunities and challenges of MOOCs to achieve SDGs in the framework of international development cooperation. From this point of departure, it is evident that the pedagogical models that universities and NGOs must assume in the implementation of MOOCs, must respond to creative approaches with active learning strategies that allow students to acquire professional competences according to current needs. The educational potential of these models also allows for the facing of problems by seeking shared solutions from different perspectives. If MOOCs are also used for professional purposes, students usually complete the training [63] thus eliminating the barrier of abandonment that is still evident in some formations [64], as our results suggest.

However, in this study, we also identified that there are still challenges to be faced, especially in the development of the SDGs, and that we still need more answers through research on how to mainstream MOOCs' effectiveness from this perspective. Weinhardt and Sitzmann [65] are committed to a future of applied research that generates a corpus of important knowledge related to the effectiveness of instruction in MOOCs. Taking our results into account, we are also committed to this, especially today, when societies worldwide face great educational and sustainable development challenges in times of pandemic.

From our reflections after a cyclical approach to the research process, it can be said that many questions in the research process remain unanswered and require greater depth and corroboration. On the one hand, it was not possible to study some issues in detail due to the holistic nature of research. At the same time, results found might be more consistent if the research had been completed with other similar case studies or more participants. Finally, the subjectivity of informants in qualitative information collection methods, along with the subjectivity of researchers in data analysis, could have produced a relative bias in the results found. It is therefore suggested that further study of the subject matter be elaborated, replicating research with other similar case studies, expanding the sample, focusing on relevant elements, and using quantitative research methods.

Author Contributions: Conceptualization, M.J.S.-D. and M.R.F.-S.; methodology, M.J.S.-D.; software, M.J.S.-D.; validation, M.J.S.-D. and M.R.F.-S.; formal analysis, M.J.S.-D.; investigation, M.J.S.-D.; resources, M.J.S.-D.; data curation, M.J.S.-D.; writing-original draft preparation, M.J.S.-D.; writing-review and editing, M.J.S.-D. and M.R.F.-S.; visualization, M.J.S.-D. and M.R.F.-S.; supervision, M.J.S.-D. and M.R.F.-S. All authors have read and agreed to the published version of the manuscript.

Funding: This research received no external funding.

Acknowledgments: We would like to thank the UNAN (Nicaragua) and the Association for Social Development of Nicaragua (ASDENIC) for their support, accessibility, and kindness in the development of the research, and all the participants for their generous help and the time they invested in participating in the study.

Conflicts of Interest: The authors declare no conflict of interest. 


\section{Appendix A}

\begin{tabular}{|c|c|c|}
\hline Elements That Can Be Studied & Questions & Participants \\
\hline $\begin{array}{l}\text { Development cooperation project: } \\
\text { origin, objectives, context, needs, } \\
\text { formality of training. }\end{array}$ & $\begin{array}{l}\text { What is the mission of ASDENIC? } \\
\text { What are the established lines of work? } \\
\text { What cooperation projects are being } \\
\text { carried out? } \\
\text { What does the agreement with the UNAN } \\
\text { consist of? } \\
\text { Why develop a MOOC? How does one } \\
\text { define what a MOOC project is? } \\
\text { How does the MOOC project originate? } \\
\text { What is the context in which the MOOC } \\
\text { project is started and what are its needs? } \\
\text { What objectives are set out with this project? } \\
\text { Do you think they have been achieved? } \\
\text { What is the evidence? }\end{array}$ & $\begin{array}{l}\text { Those responsible for the } \\
\text { interview and managers, } \\
\text { teacher focus group. }\end{array}$ \\
\hline $\begin{array}{l}\text { Methodological aspects: } \\
\text { features, improvements, theory, } \\
\text { evaluation, teaching materials. }\end{array}$ & $\begin{array}{l}\text { Can you describe the didactic methodology } \\
\text { that is carried out in MOOCs? } \\
\text { Do you think the methodology used is } \\
\text { appropriate? Why? } \\
\text { Do you think the methodology used } \\
\text { encourages creativity? Why? } \\
\text { Is the methodology motivating for the } \\
\text { student? Why? } \\
\text { Does the methodology encourage student } \\
\text { reflection with regards to what content they } \\
\text { should learn? } \\
\text { Was this methodology interesting and } \\
\text { useful? Why? } \\
\text { Do you think the assessment was } \\
\text { adequate? Why? } \\
\text { How does the teacher follow up } \\
\text { (continuous or training assessment)? } \\
\text { How does the teacher complete the final } \\
\text { evaluation (summative assessment)? } \\
\text { What are the teaching materials you } \\
\text { have used? } \\
\text { Do you have free access to the materials? } \\
\text { Do you think part of your learning is owed } \\
\text { to the quality of the materials? } \\
\text { Would you change any aspect of the digital } \\
\text { materials that you have downloaded? }\end{array}$ & $\begin{array}{l}\text { Student interviews, teacher } \\
\text { focus group }\end{array}$ \\
\hline $\begin{array}{l}\text { Learning community assessment: } \\
\text { communication, collaboration, } \\
\text { teacher and student roles. }\end{array}$ & $\begin{array}{l}\text { Is interaction or communication between } \\
\text { students and helpers programmed? What } \\
\quad \text { about the faculty? } \\
\text { What does the communication between } \\
\text { faculty and students consist of, or that } \\
\text { among students? } \\
\text { Has there been ongoing communication } \\
\text { between faculty and students, or } \\
\text { among students? } \\
\text { Is this communication and interaction } \\
\text { leading to the creation of learning or } \\
\text { community networks? }\end{array}$ & $\begin{array}{l}\text { Student interviews, } \\
\text { teacher interviews }\end{array}$ \\
\hline
\end{tabular}




\begin{tabular}{|c|c|c|}
\hline Elements That Can Be Studied & Questions & Participants \\
\hline $\begin{array}{l}\text { Learning and academic results: } \\
\text { acquired professional skills, } \\
\text { abandonment, promotion of } \\
\text { reflection in learning, accreditation } \\
\text { and certification of the course. }\end{array}$ & $\begin{array}{c}\text { Have you acquired the professional } \\
\text { competencies you expected? } \\
\text { Has content reflection been encouraged? } \\
\text { In which activities is this reflection evident? } \\
\text { Do you think your creativity has improved? } \\
\text { Why? In which activities is this } \\
\text { creativity evident? } \\
\text { Do you think collaborative learning is } \\
\text { taking place? In which activities is this } \\
\text { collaborative learning evident? } \\
\text { Is course certification and accreditation } \\
\text { offered? Which jobs can they give you } \\
\text { access to? }\end{array}$ & $\begin{array}{l}\text { Those responsible for the } \\
\text { interview and managers, } \\
\text { teacher Focus group, } \\
\text { student interviews }\end{array}$ \\
\hline $\begin{array}{l}\text { Development of the individual } \\
\text { and the environment: } \\
\text { Influence on the life of the subject, } \\
\text { in the environment, work, social } \\
\text { life, professional recognition, } \\
\text { professional skills, } \\
\text { academic results. }\end{array}$ & $\begin{array}{l}\text { Do you think the realization of formative } \\
\text { action has influenced the subject's } \\
\text { personal life? } \\
\text { What are the aspects that have improved } \\
\text { his/her personal life? } \\
\text { Do you think the student is more prepared } \\
\text { to find a better job? } \\
\text { Could taking the training action improve } \\
\text { student professional recognition? } \\
\text { Does this course influence the student's } \\
\text { environment? What is this influence? } \\
\text { Positive or negative? } \\
\text { Has his/her life improved? In what sense? }\end{array}$ & $\begin{array}{l}\text { Student interviews, } \\
\text { teacher interviews }\end{array}$ \\
\hline Student satisfaction. & $\begin{array}{l}\text { Has the formative action met } \\
\text { your expectations? } \\
\text { What positive aspects stand out from the } \\
\text { training you received? } \\
\text { What negative aspects stand out from the } \\
\text { training you received? } \\
\text { Do you think any aspect of the MOOC } \\
\text { should be changed? } \\
\text { What proposal would you make to improve } \\
\text { the training course? }\end{array}$ & Student interviews \\
\hline
\end{tabular}

\section{References}

1. Allen, S.; Cunliffe, A.L.; Easterby-Smith, M. Understanding Sustainability through the Lens of Ecocentric Radical-Reflexivity: Implications for Management Education. J. Bus. Ethics 2019, 154, 781-795. [CrossRef]

2. Kemper, J.A.; Ballantine, P.W.; Hall, C.M. The role that marketing academics play in advancing sustainability education and research. J. Clean. Prod. 2020, 248, 119229. [CrossRef]

3. Fianu, E.; Blewett, C.; Ampong, G.O. Toward the development of a model of student usage of MOOCs. Educ. Train. 2020, 62, 521-541. [CrossRef]

4. DuBois, B.; Krasny, M.E.; Russ, A. Online professional development for environmental educators: Strategies to foster critical thinking and social interactions. Environ. Educ. Res. 2019, 25, 1479-1494. [CrossRef]

5. Li, C.; Zhou, H. Enhancing the Efficiency of Massive Online Learning by Integrating Intelligent Analysis into MOOCs with an Application to Education of Sustainability. Sustainability 2018, 10, 468. [CrossRef]

6. Spanish Global Compact Network. Informe de Progreso de la Red Española del Pacto Mundial; Organización de Naciones Unidas: New York, NY, USA, 2019.

7. Pipere, A.; Veisson, M.; Salīte, I. Developing Research in Teacher Education for Sustainability: UN DESD via the Journal of Teacher Education for Sustainability. J. Teach. Educ. Sustain. 2015, 17, 5-43. [CrossRef]

8. Reunamo, J.; Pipere, A. Doing research on education for sustainable development. Int. J. Sustain. High. Educ. 2011, 12, 110-124. [CrossRef] 
9. Fernández, L.; Gutiérrez, M. Bienestar Social, Económico y Ambiental para las Presentes y Futuras Generaciones. Inf. Tecnológica 2013, 24, 121-130. [CrossRef]

10. Moore, J. Seven recommendations for creating sustainability education at the university level: A guide for change agents. Int. J. Sustain. High. Educ. 2005, 6, 326-339. [CrossRef]

11. Orr, D.W. What is higher education for now. In State of the World 2010: Transforming Cultures from Consumerism to Sustainability; Norton: New York, NY, USA, 2010; pp. 75-82.

12. Sulkowski, A.J.; Kowalczyk, W.; Ahrendsen, B.L.; Kowalski, R.; Majewski, E. Enhancing sustainability education through experiential learning of sustainability reporting. Int. J. Sustain. High. Educ. 2020, 21, 1233-1247. [CrossRef]

13. Carricondo, R.; Molero, J.; Sánchez, C.; Tomás, M.; Gómez, M.L.; Perea, O.D. Las ONG ante los Objetivos de Desarrollo Sostenible; Red Española del Pacto Mundial: Madrid, Spain, 2019.

14. Gómez, C. Objetivos de Desarrollo Sostenible (ODS): Una revisión crítica. Pap. Relac. Ecosociales Cambio Glob. 2018, 140, 107-118.

15. Bonilla-Molina, L. Apagón Pedagógico Global (APG). Las reformas educativas en clave de resistencias Viento Sur 2016, 147, 90-101.

16. Beringer, A.; Adomßent, M. Sustainable university research and development: Inspecting sustainability in higher education research. Environ. Educ. Res. 2008, 14, 607-623. [CrossRef]

17. Menon, S.; Suresh, M. Synergizing education, research, campus operations, and community engagements towards sustainability in higher education: A literature review. Int. J. Sustain. High. Educ. 2020, 21, 1015-1051. [CrossRef]

18. Michel, J.O.; Holland, L.M.; Brunnquell, C.; Sterling, S. The Ideal Outcome of Education for Sustainability: Transformative Sustainability Learning. New Dir. Teach. Learn. 2020, 2020, 177-188. [CrossRef]

19. Calvo, S.; Lyon, F.; Morales, A.; Wade, J. Educating at Scale for Sustainable Development and Social Enterprise Growth: The Impact of Online Learning and a Massive Open Online Course (MOOC). Sustainability 2020, 12, 3247. [CrossRef]

20. Gallagher, S. Development Education on a Massive Scale: Evaluations and Reflections on a Massive Open Online Course on Sustainable Development Sustentable. Policy Pract. Dev. Educ. Rev. 2018, 26, 122-140.

21. McGreal, R. Special Report on the Role of Open Educational Resources in Supporting the Sustainable Development Goal 4: Quality Education Challenges and Opportunities. Int. Rev. Res. Open Distrib. Learn. 2017, 18. [CrossRef]

22. Yuan, L.; Powell, S.J. MOOCs and Open Education: Implications for Higher Education. Cetis Inc.: Milton Keynes, UK, 2013.

23. Laurillard, D.; Kennedy, E. The Potential of MOOCs for Learning at Scale in the Global South; Centre for Global Higher Education: Lancaster, UK, 2017.

24. Valverde Berrocoso, J. MOOCS: Una visión crítica desde las Ciencias de la Educación | Profesorado, Revista de Currículum y Formación del Profesorado. Rev. Curric. Form. Profr. 2014, 18, 93-111.

25. Wang, Y.; Baker, R. Grit and Intention: Why Do Learners Complete MOOCs? Int. Rev. Res. Open Distrib. Learn. 2018, 19. [CrossRef]

26. Zancanaro, A.; Domingues, M.J. Análisis de la literatura científica sobre los cursos en línea abiertos y masivos (MOOC). RIED Rev. Iberoam. Educ. Distancia 2017, 20, 59-80.

27. Zawacki-Richter, O.; Bozkurt, A.; Alturki, U.; Aldraiweesh, A. What Research Says About MOOCs-An Explorative Content Analysis. Int. Rev. Res. Open Distrib. Learn. 2018, 19. [CrossRef]

28. Fernandez-Diaz, E.; Rodriguez-Hoyos, C.; Dominguez, J.L.B.; Salvador, A.C. Who Takes a MOOC? Profile of Students in the Framework of a European Project. Turk. Online J. Distance Educ. 2020, 21, 1-16. [CrossRef]

29. Barth, M.; Burandt, S. Adding the "e-" to Learning for Sustainable Development: Challenges and Innovation. Sustainability 2013, 5, 2609-2622. [CrossRef]

30. Chen, C.-C. Opportunities and Challenges of MOOCS: Perspectives from Asia. IFLA WLIC: Singapore, 2013.

31. Zhan, Z.; Fong, P.S.W.; Mei, H.; Chang, X.; Liang, T.; Ma, Z. Sustainability Education in Massive Open Online Courses: A Content Analysis Approach. Sustainability 2015, 7, 2274-2300. [CrossRef]

32. Aksela, M.; Wu, X.; Halonen, J. Relevancy of the Massive Open Online Course (MOOC) about Sustainable Energy for Adolescents. Educ. Sci. 2016, 6, 40. [CrossRef]

33. Wolfenden, F.; Cross, S.; Henry, F. MOOC Adaptation and Translation to Improve Equity in Participation. J. Learn. Dev. 2017, 4, 127-142. 
34. Mercier, J.-R. Exploring the Potential of Online Courses to Develop Capacity for Sustainable Development. J. Learn. Dev. 2014, 1. Available online: https://j14d.org/index.php/ej14d/article/view/63 (accessed on 25 February 2020).

35. Sachs, J.D. The Age of the Sustainable Development; Columbia University Press: New York, NY, USA, 2015.

36. Durall Gazulla, E.; Gros Salvat, B.; Maina, M.F.; Johnson, L.; Adams, S. Perspectivas Tecnológicas: Educación Superior en Iberoamérica 2012-2017; The New Media Consortium: Austin, TX, USA, 2012; ISBN 978-0-9846601-9-3.

37. Capdevila Pagès, R.; Aranzadi Elejabeitia, P. Los Cursos Online Masivos Y Abiertos: ¿Oportunidad O Amenaza Para Las Universidades Iberoamericanas? RIED Rev. Iberoam. Educ. Distancia 2014, 17, 69-82. [CrossRef]

38. Matías González, H.; Pérez Avila, A. Los Cursos en Línea Masivos y Abiertos (MOOC) como alternativa para la educación a distancia (Massive Open Online Courses (MOOC), an alternative to distance learning). GECONTEC Rev. Int. Gest. Conoc. Tecnol. 2014, 2, 41-49.

39. Bartholet, J. Hype and hope. Sci. Am. 2013, 309, 53-61. [CrossRef] [PubMed]

40. Díaz, Y.; Baena, M.A.; Baena, G.R. MOOC en la educación: Un acercamiento al estado de conocimiento en Iberoamérica, 2012-2017. RIDE Rev. Iberoam. Investig. Desarro. Educ. 2017, 8, 259-278.

41. Kim, Y. The Framework of Cloud e-Learning System for Strengthening ICT Competence of Teachers in Nicaragua. Int. J. Adv. Sci. Eng. Inf. Technol. 2018, 8, 62-67. [CrossRef]

42. Stake, R.E. Investigar con Estudios de caso; Morata: Madrid, Spain, 1998.

43. Denzin, N.K.; Lincoln, Y.S. The Sage Handbook of Qualitative Research; Sage Publications Ltd.: Thousand Oaks, CA, USA, 2011.

44. Sabariego, M.; Dorio, I.; Massot, M.I. Métodos de investigación cualitativa. In Metodología de la Investigación Educativa; La muralla: Madrid, Spain, 2004; pp. 293-328.

45. Latorre, A. La Investigación-Acción. Conocer y Cambiar la Práctica Educativa; Grao: Barcelona, Spain, 2003.

46. Cohen, L.; Manion, L. Métodos de investigación educativa; La muralla: Madrid, Spain, 1990.

47. Taylor, S.J.; Bogdan, R. Introducción a los Métodos Cualitativos de Investigación; Paidós: Barcelona, Spain, 1986.

48. Glaser, B.; Strauss, A. The Discovery of Grounded Theory: Strategies for Qualitative Research; Aldine de Gruyter: New York, NY, USA, 1967.

49. Trinidad, A.; Carrero, V.; Soriano, R.M. Teoría Fundamentada "Grounded Theory". La construcción de la teoría a Través del Análisis Interpretacional; Centro de Investigaciones Sociológicas: Madrid, Spain, 2006.

50. Glaser, B. Doing Grounded Theory; Sociology Press: Mill Valley, CA, USA, 1998.

51. Strauss, A.; Corbin, J. Bases de la Investigación Cualitativa. Técnicas y Procedimientos para Desarrollar la Teoría Fundamentada; Universidad de Antioquía: Antioquia, Colombia, 2002.

52. Abela, J.A.; García-Nieto, A.; Pérez, A. Evolución de la Teoría Fundamentada como Técnica de Análisis Cualitativo; Centro de Investigaciones Sociológicas: Madrid, Spain, 2007.

53. Conde, F. Análisis Sociológico del Sistema de Discurso; Centro de Investigaciones Sociológicas: Madrid, Spain, 2009.

54. Hernández, R.; Fernández-Collado, C.; Baptista, P. Metodología de la Investigación; McGraw-Hill: Ciudad de México, México, 2006.

55. Conole, G.; Galley, R.; Culver, J. Frameworks for understanding the nature of interactions, networking, and community in a social networking site for academic practice. Int. Rev. Res. Open Distrib. Learn. 2011, 12, 119-138. [CrossRef]

56. Poy, R.; Gonzales-Aguilar, A. MOOC success factors: Some critical considerations. RISTI Rev. Ibérica Sist. Tecnol. Inf. 2014, 1, 105-118.

57. Askeroth, J.H.; Richardson, J.C. Instructor Perceptions of Quality Learning in MOOCs They Teach. Online Learn. 2019, 23. [CrossRef]

58. Ebben, M.; Murphy, J.S. Unpacking MOOC scholarly discourse: A review of nascent MOOC scholarship. Learn. Media Technol. 2014, 39. [CrossRef]

59. Rodriguez, O. The concept of openness behind c and x-MOOCs (Massive Open Online Courses). Open Prax. 2013, 5, 67-73. [CrossRef]

60. Ichimura, Y.; Suzuki, K. Dimensions of MOOCs for Quality Design: Analysis and Synthesis of the Literature. Int. J. Educ. Media Technol. 2017, 11, 42-49. 
61. Villardón, P.G.; Galindo, P.V. Elementos del diseño pedagógico del MOOC «estadística para investigadores». Aula 2017, 23, 287-301. [CrossRef]

62. Zapata-Ros, M. El diseño instruccional de los MOOC y el de los nuevos cursos abiertos personalizados. Rev. Educ. Distancia 2015, 45, 1-35. [CrossRef]

63. Greene, J.A.; Oswald, C.A.; Pomerantz, J. Predictors of retention and achievement in a massive open online course. Am. Educ. Res. J. 2015, 52, 925-955. [CrossRef]

64. Lee, D.; Watson, S.L.; Watson, W.R. Systematic literature review on self-regulated learning in massive open online courses. Australas. J. Educ. Technol. 2019, 35. [CrossRef]

65. Weinhardt, J.M.; Sitzmann, T. Revolutionizing training and education? Three questions regarding massive open online courses (MOOCs). Hum. Resour. Manag. Rev. 2019, 29, 218-225. [CrossRef]

Publisher's Note: MDPI stays neutral with regard to jurisdictional claims in published maps and institutional affiliations.

(C) 2020 by the authors. Licensee MDPI, Basel, Switzerland. This article is an open access article distributed under the terms and conditions of the Creative Commons Attribution (CC BY) license (http://creativecommons.org/licenses/by/4.0/). 